\title{
Assessing the value of household work based on wages demanded on online platforms for substitutes
}

\author{
Simona Jokubauskaitè ${ }^{1} \cdot$ Alyssa Schneebaum $\mathbb{D}^{2}$
}

Received: 30 June 2020 / Accepted: 11 January 2021 / Published online: 6 February 2021

(c) The Author(s) 2021; This article is published with open access

\begin{abstract}
We propose an improved method to assess the economic value of unpaid housework and childcare. Existing literature has typically assigned a minimum, generalist or specialist's wage, or the performer's opportunity cost to the hourly value of these activities. Then it was used to calculate macro-level value based on the number of hours spent in this work. In this paper, instead of imputing an average or minimum wage for housework and childcare to determine a value to the work, we use the actual local wage rate requested for these services from providers on online platforms. Applying this method to Austrian Time Use Survey data shows that the value of unpaid childcare and housework, had it been paid, would be equivalent to about $22 \%$ of the 2018 GDP.
\end{abstract}

Keywords Unpaid work · Valuation · Domestic work $\cdot$ Housework $\cdot$ Care work

JEL Classification C81 $\cdot \mathrm{J} 22 \cdot \mathrm{J} 13 \cdot \mathrm{G} 59$

\section{Introduction}

No economy would function without adequate care for young children (who will grow to become economic agents) or the housework necessary to sustain people. Since care- and housework in one's own home is largely unpaid, it is unclear how to measure the economic value of this work. To understand the economics of the household, though, it is important to understand better the economic value of the work produced within it.

Alyssa Schneebaum

alyssa.schneebaum@wu.ac.at

1 Institute of Statistics, University of Natural Resources and Life Sciences, Peter-Jordan-Straße 82/I, 1190 Vienna, Austria

2 Department of Economics, Vienna University of Economics and Business, Welthandelsplatz 1, 1020 Vienna, Austria 
The literature quantifying the worth of house- and care work ${ }^{1}$ assigns a value to the number of hours spent in this work (most commonly calculated using time-use surveys) in one of three main ways. On the one hand, there are two "input" methods: the opportunity cost approach and the market replacement cost approach. On the other hand, there is an "output" method. The first of these three - the opportunity cost approach - assumes that time spent on unpaid work is at the expense of earning a market wage. Many calculations of opportunity costs simply use an average wage rate of all employed people (Ahmad \& Koh, 2011); others estimate a potential wage rate even for people outside the paid labor force (Gammage, 2010; Schmid et al., 1999). The second approach - the market replacement approach - imputes wages that reflect the market price of the respective tasks, using either the average wage rate of a general housekeeper (Ahmad \& Koh, 2011; Varjonen et al., 2014) or including multiple wage rates of specialists in matched occupations (Hamdad, 2003; Landefeld et al., 2005). Sometimes, calculations with minimum wages for these tasks are included to provide lower-bound estimates (Landefeld et al., 2005). Some studies using the market replacement approach also account for the intensity of care (e.g. physical and development care) and incorporate supervisory care (Suh \& Folbre, 2016; Mullan, 2010). Finally, the output approach quantifies the value of the output of unpaid work, measuring the service price of, for example, a kilogram of washing or ironing (Holloway et al., 2002), or a child taken care of (Mullan, 2010; Yoon, 2014). In practice, many studies in the literature calculate a value of unpaid work using more than just one of these methods, providing instead a battery of potential wage rates in order to give a range of estimates for the value of domestic and care work. The fact that many studies report values calculated with several different approaches speaks to the lack of any "best" practice in this literature.

In considering how to better and consistently quantify the value of unpaid houseand care work, we propose a new approach to introduce more precision into wage estimates in the specialist replacement cost method. In particular, we use the wages demanded for housework and childcare on actual online platforms to get the market price of the work performed, disaggregated by region at the NUTS-2 level. We then apply these values to region-specific time-use statistics to compute the aggregate value of the work.

The use of online platforms to organize work has become increasingly prevalent (see, for example, Katz and Krueger (2019) and Kässi and Lehdonvirta (2018)), not least to match households with babysitters and cleaners. Our approach thus allows the literature to keep up with the changing nature of the organization and payment for this work. National accounting offices, who are already working to supplement GDP measures with satellite accounts (European Communities, 2003), can find our approach particularly useful.

In relation to other literature on this topic, we consider our approach to fit into the specialist framework, in that we assume that it is specialists who offer childcare and cleaning services on online platforms. Table 1 shows that there are varying degrees of "specialization" among the workers on the platforms we use; those with more years of experience also demand higher wages.

\footnotetext{
${ }^{1}$ We use the terms "housework" and "domestic" work interchangeably, and always differentiate these activities from childcare. Childcare and housework/domestic work are defined in footnote 3 below.
} 
Table 1 Distribution of advertisements by years of experience $^{\mathrm{a}}$

\begin{tabular}{llllll}
\hline & \multicolumn{2}{l}{ Domestic } & & & \multicolumn{2}{l}{ Childcare } \\
\cline { 2 - 3 } \cline { 5 - 6 } Experience & Mean & $\mathrm{N}$ & & Mean & $\mathrm{N}$ \\
\hline $0-4$ & 11.18 & 6555 & & 10.58 & 8975 \\
$5-9$ & 11.57 & 3377 & & 10.94 & 3625 \\
$10+$ & 11.96 & 4518 & & 11.66 & 2070 \\
\hline
\end{tabular}

${ }^{a}$ Not all workers used in the main analysis below indicate their years of experience

The benefits of the calculation method described here are five-fold. First, our approach does not rely on hypothetical considerations about the value of the worker's time to measure an opportunity cost of doing the work, estimates of which differ widely based on education, professional experience, and socioeconomic background (Schmid et al., 1999). Instead, our approach takes the value of the work to be the market value that the worker herself demands. Second, our approach uses relatively local wage rates (NUTS-2 level), meaning that the application of our method would produce more accurate local estimates of the value of household and care work. Third, the approach avoids applying a minimum wage to a job that may actually receive higher remuneration, making it more accurate. Fourth, the wage data are reported per hour, unlike in labor force surveys, where hourly wage data are often imprecisely computed because they are calculated using other variables such as yearly income, hours worked per week, and weeks worked per year. Finally, our approach uses free and real-time data on wages paid, instead of relying on this information from labor force surveys. The latter are costly in terms of time as well as money and their publication typically has a long delay after data collection. Researchers can use our method in any country that collects time-use data and in which there are platforms organizing these services.

In the next section, we show an application of our method with the wage data collected from online platforms. We estimate the aggregated value of typically unpaid work by applying wage rates to time-use data from the same region.

\section{Application}

We use data from Austria for our empirical application. Data on time-use come from the $2008-2009^{2}$ time-use survey (TUS) conducted by Statistik Austria (2020). According to the TUS, the following tasks are considered housework: cooking, cleaning, laundry, gardening, repairs, shopping for the household, household management, travel related to housework, and other housework activities. Childcare comprises primary care of the child, helping with the child with schoolwork, recreation with the child, accompanying the child to appointments, travel related to

\footnotetext{
2 There are more recent time-use data for Austria available from the Mobility-Activity-Expenditure Diary (MAED) survey conducted in 2015, but these data comprise only 748 individuals and do not report childcare as a separate activity. As reported in Hössinger et al. (2019), time-use patterns did not change significantly between the national time use survey in 2008/2009 and the MAED survey in 2015, and there is no reason to suspect that it would have changed significantly in the time to 2019 .
} 
Table 2 Time spent in childcare and housework (minutes/day), 15-64 year olds

\begin{tabular}{llrrrrrrrr}
\hline & & \multicolumn{3}{c}{ Primary activity only } & & \multicolumn{3}{c}{ Primary and secondary } \\
Segment (N) & Activity & Total & Women & Men & & Total & Women & Men \\
\hline \multirow{2}{*}{ Total (6215) } & Childcare & 34.0 & 46.8 & 18.7 & & 43.1 & 60.1 & 22.7 \\
& Housework & 172.6 & 224.6 & 110.3 & & 182.0 & 238.2 & 114.5 \\
\multirow{3}{*}{ w/ children (1542) } & Childcare & 117.0 & 156.3 & 66.1 & 148.0 & 200.4 & 80.0 \\
& Housework & 175.7 & 239.3 & 93.3 & 188.3 & 257.7 & 98.5 \\
w/o children (4673) & Childcare & 6.6 & 9.0 & 3.9 & 8.5 & 11.7 & 4.8 \\
& Housework & 171.6 & 219.5 & 115.6 & 179.9 & 231.4 & 119.5 \\
\hline
\end{tabular}

childcare, and other childcare activities. These activities likely make up a large portion of all activities related to domestic and childcare work. However, any other kind of work in these areas is not captured in our wage calculations - which implies that our estimates are a lower-bound value for domestic and childcare work. Table 2 shows the average number of minutes spent per day on childcare and household work for 15-64 year olds. It is calculated based on whether the activity was primary or secondary (the latter are activities that are done simultaneously with the primary activity, such as listening to music while primarily cooking). Individuals in the survey spent on average about $34 \mathrm{~min}$ in childcare and $172 \mathrm{~min}$ in household work per day. Disaggregating these figures into households with and without children under 10 reveals that-not surprisingly-those with children spent on average almost $2 \mathrm{~h}$ more on childcare. Parents spend "only" $2 \mathrm{~h}$ per day on childcare because the Austrian Time Use Survey does not include information on supervisory responsibilities that encompasses activities like being present while a child naps. The survey thus cannot capture the element of childcare that relates to the worth of what care work prevents a caregiver from doing, such as working for pay outside of the home.

To calculate the monetary value of this work, we use two prominent online platforms to obtain the wages for housework and childcare: www.haushaltshilfe24.at (household help 24) and www.babysitter24.at, respectively. These sites are intended for private, individual users (both suppliers and demanders of housework and childcare services), but some agencies may covertly find work for their employees via these platforms.

In June 2019 we collected data on the wages demanded from workers offering childcare and housework ${ }^{3}$ services. The listings on these websites give an hourly wage, which we use in our calculations. Some of the arrangements are for one-time jobs, while others may be requesting repeated work, such as weekly babysitting. We take the hourly wage as listed, regardless of the regularity with which the work was meant to be completed. In addition, the data from the listings do not allow us to differentiate between work to be completed during regular business hours versus other times of the

\footnotetext{
${ }^{3}$ Cooking is a prominent activity in the time-use data, which may be too particular to include in the general housework category. To test this, we used the fact that some workers mention their willingness to cook in their personal descriptions on the websites. We divided our sample into advertisements with and without cooking and performed a t-test for independent samples. The results show that there is no statistically significant difference in wages between these two groups. Thus, the mean wage used in the analysis was constructed from all available activities without further differentiating cooking.
} 
Table 3 Number of advertisements by NUTS-2 region in Austria

\begin{tabular}{lrrrrr}
\hline & \multicolumn{2}{c}{ Domestic } & & & \multicolumn{2}{c}{ Childcare } \\
\cline { 2 - 3 } & Women & Men & & Women & Men \\
\hline All & 12,871 & 1584 & & 14,041 & 753 \\
Vienna & 5003 & 633 & & 5796 & 425 \\
Lower Austria & 1881 & 233 & & 2046 & 100 \\
Styria & 1781 & 207 & & 1583 & 65 \\
Upper Austria & 1728 & 221 & & 1525 & 61 \\
Carinthia & 639 & 82 & & 695 & 21 \\
Tyrol & 595 & 69 & & 983 & 32 \\
Salzburg & 573 & 75 & & 679 & 28 \\
Burgenland & 423 & 39 & & 331 & 8 \\
Vorarlberg & 248 & 25 & & 403 & 13 \\
\hline
\end{tabular}
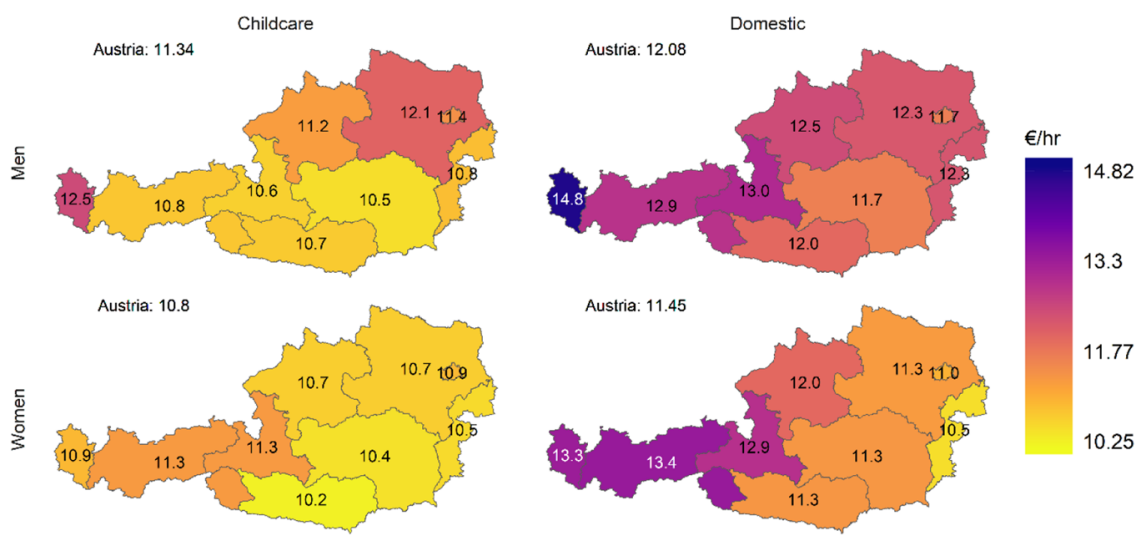

Fig. 1 Average wage rates of domestic work, EUR/h

day, like overnight care shifts, though the latter could be paid differently than daytime work. We cannot specify whether these wages are the worker's gross wages or net of taxes, because tax payments depend on total income. Workers with very low income do not pay any income taxes; some of the workers offering services on this platform may fall into this group, while others will have to pay taxes on their income.

We filtered listings according to postal area and worker gender. It would have been interesting to further observe wages for immigrant versus native workers, but the data do not contain information on country of origin or family migration background. We took the wages demanded from around 15,000 observations from each online platform. Almost $90 \%$ of advertisements offering services come from women (Table 3). We calculate the average wage demanded for household work and childcare at the NUTS-2 level, for each of the nine regions of Austria (Fig. 1).

Figure 1 shows the average wage rate demanded for household work and for babysitting services, broken down by gender and region. There is significant variation in the hourly wage of these services across regions, but overall, an hour of childcare costs about $€ 11$ and household work costs closer to $€ 12$. Interestingly, the 
Table 4 Average value of domestic work as percentage of GDP

\begin{tabular}{lrrr}
\hline Activities included & Women & Men & Total \\
\hline Primary activity only & & & \\
Total & 14.21 & 7.41 & 21.62 \\
Childcare & 2.23 & 0.94 & 3.17 \\
Housework & 11.98 & 6.47 & 18.45 \\
Both, weighted & & & \\
Total & 9.06 & 4.62 & 13.68 \\
Childcare & 1.58 & 0.64 & 2.22 \\
Housework & 7.48 & 3.98 & 11.46 \\
Primary and secondary $_{\text {Total }}$ & & & \\
Childcare & 15.54 & 7.84 & 23.39 \\
Housework & 2.83 & 1.13 & 3.96 \\
\hline
\end{tabular}

${ }^{a}$ Time spent on the activity was weighted by 0.6 if it was a primary activity and by 0.4 if it was a secondary activity, as suggested in Apps and Rees (2011, FN 24). These weights were only used in the row "both, weighted" in the ablet; the data in the other rows were unweighted

average hourly wage demanded by men on these platforms is higher than the wage demanded by women.

\section{A macro-level estimate for the value of unpaid work}

We next apply the region-specific average wage rates to the average time spent on household and childcare activities in each region. The goal of this exercise is to determine the value of the work as a percentage of GDP, which is the standard measure of the value of unpaid work in the literature. We use the most recent GDP data at the time of research available for Austria, namely data from 2018, which was equal to about $€ 386$ billion. There is a 1 -year mismatch in the time dimensions of our wage and GDP data; the platform wage data were collected in 2019 and the most recent GDP figures are from 2018. To correct this mismatch, we deflate the wage rates using the national consumer price index, ${ }^{4}$ Table 4 presents results of our final percentage estimates.

When considering primary activities only, we find that the value of housework and childcare amounts to about $22 \%$ of the 2018 GDP; when using both primary and secondary activities, the value is near 23.4\%. Ahmed and Koh (2011) have also calculated the value of labor for domestic and care work in Austria compared to the total value of the 2008 GDP using the same time-use data, but with different valuation methods and wage data (in particular, OECD PPP wage data) and including several activities not used in our study (in particular, care for adult household

\footnotetext{
${ }^{4}$ We use the country-level consumer price index to deflate the wage rate. It would have been beneficial to deflate prices at the regional level but region-specific consumer price indices are unavailable for Austria.
} 
members, care for non-household members, and volunteer work). Using average generalist wages for primary activities, they estimate that labor costs for housework and care work was equivalent to $24 \%$ of GDP in 2008. When using instead an opportunity cost approach, the estimate is $41 \%$ of GDP in 2008. Schappelwein (2018) has applied the generalist approach to the same Austrian time-use data but with data on net wages from European Union Survey on Income and Living Conditions. She computed a labor value for housework and care of dependent people (children and others) equivalent to $27 \%$ of GDP in 2008. These comparisons - which all use the same time-use data - show that the valuation of domestic work is sensitive to the methodological approach and, crucially, the wage data employed. We argue that our approach is superior to previous methods, primarily because it uses what is likely the closest true value of the market cost of an hour of this work. In addition, with more widespread use of the internet, more services will be offered online and thus the estimates of wage rates using our method will improve.

\section{Discussion}

The main contribution of this paper has been to introduce a new approach to the valuation of domestic work. By using easily accessible and free information on actual wages, our method helps form a better understanding of the market value of household work and childcare. Calculating this worth sheds light on the economic value of such work. We find that this work would be additionally worth about $22 \%$ of GDP if it were paid at going market prices; this estimate is close to the value created by the industry sector in Austria. The approach proposed in this paper can be particularly useful to national accounting offices while developing household-specific satellite accounts to supplement measures of the gross domestic product.

Acknowledgements We thank Nancy Folbre, Katharina Mader, and Jooyeoun Suh for helpful comments. Carla Rainer provided excellent research assistance. Open Access funding provided by Vienna University of Economics and Business (WU).

\section{Compliance with ethical standards}

Conflict of interest The authors declare that they have no conflict of interest.

Publisher's note Springer Nature remains neutral with regard to jurisdictional claims in published maps and institutional affiliations.

Open Access This article is licensed under a Creative Commons Attribution 4.0 International License, which permits use, sharing, adaptation, distribution and reproduction in any medium or format, as long as you give appropriate credit to the original author(s) and the source, provide a link to the Creative Commons license, and indicate if changes were made. The images or other third party material in this article are included in the article's Creative Commons license, unless indicated otherwise in a credit line to the material. If material is not included in the article's Creative Commons license and your intended use is not permitted by statutory regulation or exceeds the permitted use, you will need to obtain permission directly from the copyright holder. To view a copy of this license, visit http://creativecommons.org/licenses/by/4.0/. 


\section{References}

Ahmad, N., \& Koh, S. H. (2011). Incorporating estimates of household production of non-market services into international comparisons of material well-being. OECD Statistics Working Papers No. 2011/07.

Apps, P., \& Rees, R. (2011). Household time use, inequality and taxation. In J. A. Molina (Ed.), Household economic behaviors. Springer.

European Communities. (2003). Household production and consumption proposal for a methodology of household satellite accounts. https://ec.europa.eu/eurostat/documents/3888793/5823569/KS-CC-03003-EN.PDF/8e284578-a435-4bd8-b42d-b86d4a911637.

Gammage, S. (2010). Time pressed and time poor: Unpaid household work in Guatemala. Feminist Economics, 16(3), 79-112.

Hamdad, M. (2003). Valuing households' unpaid work in Canada, 1992 and 1998: Trends and sources of change. In Statistics Canada Economic Conference, Statistics Canada, Ottawa, (pp. 1-14).

Holloway, S, Short, S., \& Tamplin, S. (2002). Household satellite account (experimental) methodology. ONS.

Hössinger, R., Aschauer, F., Jara-Díaz, S., Jokubauskaitė, S., Schmid, B., Peer, S., Axhausen, K. W., \& Gerike, R. (2019). A joint time-assignment and expenditure-allocation model: Value of leisure and value of time assigned to travel for specific population segments. Transportation, 47, 1439-1475.

Katz, L. F., \& Krueger, A. B. (2019). The rise and nature of alternative work arrangements in the United States, 1995-2015. ILR Review, 72(2), 382-416.

Kässi, O., \& Lehdonvirta, V. (2018). Online labour index: Measuring the online gig economy for policy and research. Technological Forecasting and Social Change, 137(2018), 241-248.

Landefeld, J. S., Fraumeni, B. M., \& Vojtech, C. M. (2005). Accounting for nonmarket production: A prototype satellite account using the American time use survey. Bureau of Economic Analysis (BEA) working paper 0056 (Washington, DC: BEA, 2005), https://www.bea.gov/research/papers/2005/a ccountingnonmarket-production-prototype-satellite-account-using-american.

Mullan, K. (2010). Valuing parental childcare in the United Kingdom. Feminist Economics, 16(3), 113-139.

Schmid, H. Sousa-Poza, A., \& Widmer, R. (1999). Monetäre Bewertung der unbezahlten Arbeit: Eine empirische Analyse für die Schweiz anhand der Schweizerischen Arbeitskräfteerhebung. BFS.

Schappelwein, E. (2018). Ich seh', ich seh', was du nicht siehst: Der blinde Fleck unbezahlte Arbeit Möglichkeiten der ökonomischen Berücksichtigung am Beispiel Österreich. Master's thesis. Vienna: Vienna University of Economics and Business.

Statistik Austria. (2020). Zeitverwendungserhebung 2008/09 (erstellt im Auftrag der Bundesministerin für Frauen und Öffentlichen Dienst) [Data set]. http://www.bea.gov/research/papers/2005/accountingnonma rket-production-prototype-satellite-account-using-american

Suh, J., \& Folbre, N. (2016). Valuing unpaid child care in the US: A prototype satellite account using the american time use survey. Review of Income and Wealth, 62(4), 668-684.

Varjonen, J., Hamunen, E., \& Soinne, K. (2014). Satellite accounts on household production: Eurostat methodology and experiences to apply it. Working Papers 1/2014. Statistics Finland.

Yoon, J. (2014). Counting care work in social policy: Valuing unpaid child-and eldercare in Korea. Feminist Economics, 20(2), 65-89. 